\title{
Investigation of Solar Collector Design Parameters Effect onto Solar Stirling Engine Efficiency
}

Mohammad Hossien Ahmadi* and Hadi Hosseinzade

Faculty of Mechanical Engineering, K.N Toosi University, Tehran, Iran

\begin{abstract}
The performance of a solar-powered heat engine, operating in a Stirling cycle is studied in this work. Also the influence of design parameters on both the optimum solar receiver temperature and overall efficiency is considered. The analysis has also clearly brought out the effect of solar collector design parameters such as concentration ratio, overall heat-loss coefficient, and heat engine parameter on the overall efficiency of solar Stirling power systems.
\end{abstract}

Keywords: Solar collector; Solar Stirling engine; Concentration ratio; Radiation; Efficiency

\section{Introduction}

Thermodynamic cycles have been widely used in conversion of solar radiation energy into the electrical power. Use of solar collector systems in Stirling engine has been investigated in recent literatures [15]. Most applications of solar collector systems in Stirling engines are in space power and terrestrial power plant systems in which entirely directed at the electrical power generation. Less attention has been accomplished in small scale terrestrial applications such as in domestic application [6-12]. In recent studies [13,14] it has been identified that the Stirling engine has good potential for meeting continuous power requirements in the 5 to $20 \mathrm{~kW}$ range for electrical power generation and water pumping requirements in third world countries.

The dish-Stirling system, comprises of a parabolic dish collector (which is made up a dish concentrator and a thermal absorber) and a Stirling heat engine located at the focus of the dish, tracks the sun and focuses solar energy into a cavity absorber where solar energy is absorbed and transferred to the Stirling engine to heat its displacer hotend, thereby creating a solar powered Stirling heat engine, as shown in Figure 1.

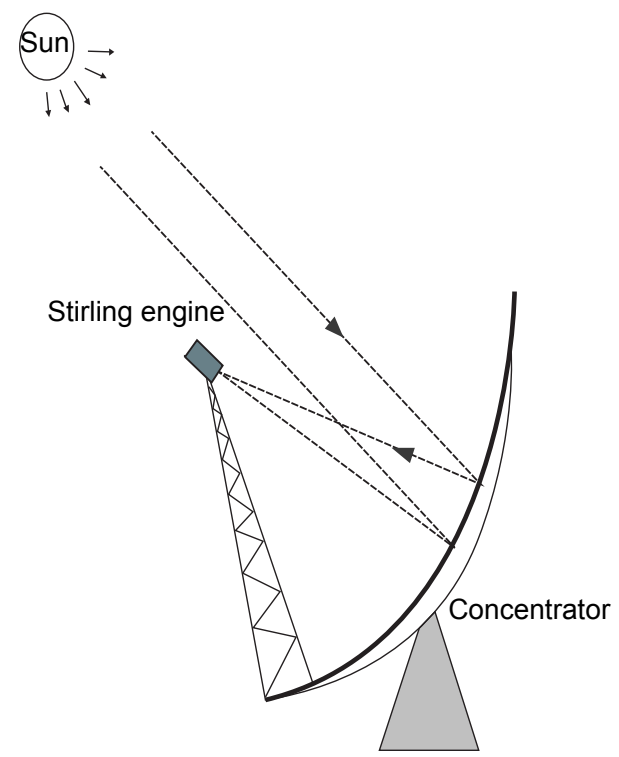

Figure 1: Schematic of a solar stirling engine.
Operation of a solar Stirling engine depends not only on the design parameters of the Stirling engine but also on the design parameters of the heat source, i.e. the solar collector. In the following, a thermodynamic analysis of a solar Stirling engine has been conducted to see the impact of solar collector design parameters on the operation of a solar Stirling engine. A theoretical approach to the determination of optimum working temperature has been described by Sootha et al. [14]. This subject has also been approached by other authors within a different scope and theoretical framework [15-24]. A study on the optimum operation of a solar converter in combination with a Stirling of Ericsson heat engine has also been conducted by Badescu [18,25].

\section{Analysis}

Solar energy is incident on a solar collector which is coupled to a Stirling engine as the heat source. The incident energy on the collector includes the direct solar radiation incident on the collector as well as the radiation absorbed from the atmosphere. The collector loses some of its energy to the surroundings by convection and radiation. The rest of the thermal energy is delivered to the Stirling engine. Therefore, the energy balance on the collector is given by [25-28].

$$
Q_{D}+Q_{O}=Q_{R}+Q_{C}+Q_{T}
$$

Where $Q_{D}$ and $Q_{O}$ are the energy fluxes absorbed from the sun (short wave) and from the atmosphere (long wave), respectively. Also, $Q_{R}$ is the flux or radiant energy emitted by the converter, $Q_{C}$ is the rate of thermal convective losses and $Q_{T}$ is the rate of thermal energy delivered to the Stirling engine.

The energy flux absorbed from the sun is

$$
Q_{D}=(\tau \alpha)_{d} I_{d}+(\tau \alpha)_{b} I_{b} C
$$

$(\tau \alpha)_{d}$ and $(\tau \alpha)_{b}$ are the receiver effective absorptance-transmittance for diffuse and direct(beam) radiation, respectively, while $C$ is

*Corresponding author: Mohammad Hossien Ahmadi, Faculty of Mechanical Engineering, K.N. Toosi University, Pardis Ave, Mollasadra street, Vanak Sq, Tehran, Iran, Zip code:19991-43344; E-mail: mohammadhosein.ahmadi@gmail.com

Received February 14, 2012; Accepted March 28, 2012; Published March 30 , 2012

Citation: Ahmadi MH, Hosseinzade H (2012) Investigation of Solar Collector Design Parameters Effect onto Solar Stirling Engine Efficiency. J Applied Mechanic Engg 1:102. doi:10.4172/2168-9873.1000102

Copyright: (c) 2012 Ahmadi MH, et al. This is an open-access article distributed under the terms of the Creative Commons Attribution License, which permits unrestricted use, distribution, and reproduction in any medium, provided the original author and source are credited. 
the concentration ratio of the direct solar radiation; $I_{d}$ and $I_{b}$ are irradiances of the solar diffuse and direct(beam) radiation, respectively.

We assume that the energy flux absorbed from the atmosphere is

$$
Q_{O}=(\tau \alpha)_{O} \sigma T_{S}^{4}
$$

Where $(\tau \alpha)_{O}$ is the effective receiver absorptance-transmittance product for atmospheric radiation; $\sigma$ is the Stefan-Boltzmann constant and $T_{S k y}$ is the equivalent black-body temperature of the sky [16-18, 25, 26,29].

$$
T_{S k y}=0.0552 T_{O}^{1.5}
$$

Where $T_{O}$ is the ambient absolute temperature. The rate of radiative energy loss from the collector is given by

$$
Q_{R}=\varepsilon \sigma T_{S B}^{4}
$$

Where $\varepsilon$ and $T$ are solar collector emissivity and temperature of the solar collector, respectively.

The rate of thermal convective losses is given by $[16-18,25,27,28]$

$$
Q_{C}=U\left(T-T_{O}\right)
$$

Where $U$ is the overall converter convective heat loss coefficient of the collector.

The thermodynamic efficiency of a Stirling cycle is given by [25]

$$
\eta_{C}=\frac{1-\frac{T_{O}}{T}}{1+D\left(1-\frac{T_{O}}{T}\right)}
$$

Where

$$
D=\frac{x C_{v}}{R \operatorname{Ln} \frac{v_{1}}{v_{2}}}
$$

And $x$ is the fractional deviation from ideal regeneration (i.e. $x=1$ for no regeneration and $x=0$ for ideal regeneration), $R$ is the gas constant, $C_{v}$ the heat capacity at constant volume of the working fluid and $v_{1}$ and $v_{2}$ are the specific volumes of the constant volume regeneration process.

Substituting values of $Q_{D}, Q_{O}, Q_{R}$ and $Q_{C}$ from equation (2)-(5) in equation (1), we have the rate of the thermal energy delivered to the Stirling engine:

$$
Q_{T}=(\tau \alpha)_{d} I_{d}+(\tau \alpha)_{b} I_{b} C+(\tau \alpha)_{O} \sigma T_{S}^{4}-\varepsilon \sigma T^{4}-U\left(T-T_{O}\right)
$$

We define the following non dimensional ratio

$$
\theta=\frac{T}{T_{O}}
$$

If $Q_{T}$ is the rate of thermal energy delivered to the Stirling engine, then the power produced by the Stirling engine is

$$
P=Q_{T} \times \eta_{C}
$$

For the maximum power production

$$
\frac{d P}{d \theta}=\frac{d}{d \theta}\left(Q_{T} \times \eta_{C}\right)=0
$$

Substituting equation (8) into (7) and then applying equation (9), we have [25]

$$
\theta^{5}-\left(\frac{3+8 D}{D+1}\right) \theta^{4}+\left(\frac{D}{D+1}\right) \theta^{3}+\frac{b}{4 a} \theta^{2}-\frac{b}{2 a}\left(\frac{D}{D+1}\right) \theta-\frac{1+L-b(D-1)}{4 a(D+1)}=0
$$

Where

$$
\begin{aligned}
& a=\frac{\varepsilon \sigma T_{0}^{4}}{(\alpha \tau)_{d} I_{d}+(\alpha \tau)_{b} I_{b} C} \\
& b=\frac{U T_{0}}{(\alpha \tau)_{d} I_{d}+(\alpha \tau)_{b} I_{b} C} \\
& L=\frac{(\alpha \tau)_{d} \sigma T_{S}^{4}}{(\alpha \tau)_{d} I_{d}+(\alpha \tau)_{b} I_{b} C}
\end{aligned}
$$

The optimum collector temperature

$T_{\text {opt }}=T_{O} \times \theta_{\text {opt }}$

The maximum efficiency of the solar Stirling engine is

$$
\eta_{\max }=\frac{P_{\max }}{Q_{D}}
$$

\section{Result and Discussion}

A selectively coated collector system with typical values of emissivity $\varepsilon=0.1$, overall heat loss coefficient $\left(\mathrm{U}=4 \mathrm{Wm}^{-2} \mathrm{~K}^{-1}\right)$, $(\alpha \tau)$ $=0.8,(\alpha \tau)_{\mathrm{d}}=0.5,(\alpha \tau)_{\mathrm{O}}=0.5$ has been considered. Figure 2 shows the dependence of the overall efficiency of a solar Stirling system on the Stirling engine parameter and the concentration ratio of the collector system. It is evident from the figure 2 that the overall efficiency of the system is less dependent on increasing values of the engine parameter and increases with the increasing concentration ratio.

Figure 3 shows the variation of the ratio of optimum operating temperature with concentration ratio for various values of engine parameters. By fixed concentration ratio and decreasing engine parameters, caused optimum operating temperature ratio increased. Also in fixed engine parameters by increasing concentration result, optimum temperature ratio increased.

Figure 4 and 5 show the influence of overall heat loss coefficient on the overall maximum efficiency of the solar Stirling power system. As is evident from figure 4, the overall maximum efficiency of a solar Stirling power system based on a flat plate collector is strongly dependent on $\mathrm{U}$

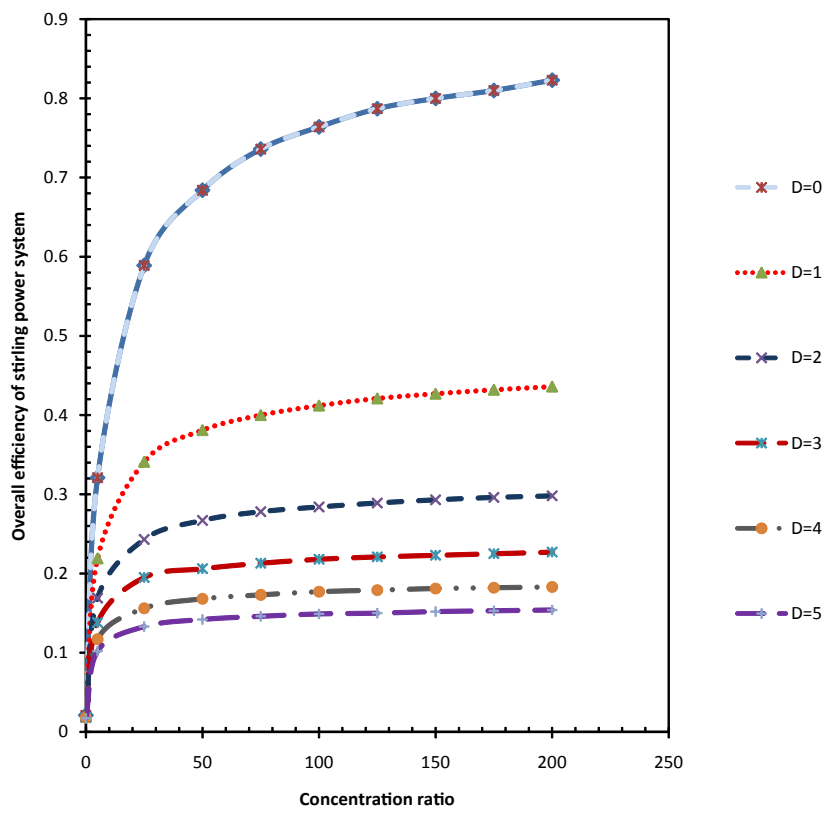

Figure 2: Dependence of the overall efficiency of the solar Stirling system on the engine parameters and the concentration ratio of the solar collector. 


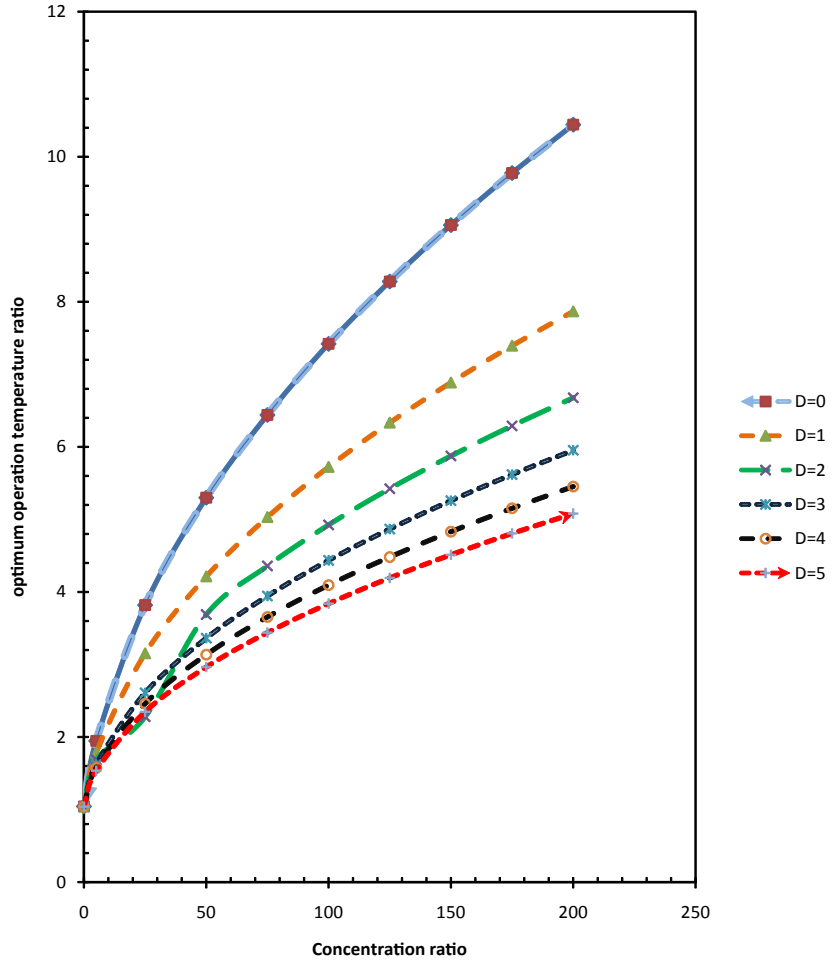

Figure 3: Dependence of the optimum operating temperature ratio on the engine parameters and the concentration ratio of the solar collector.

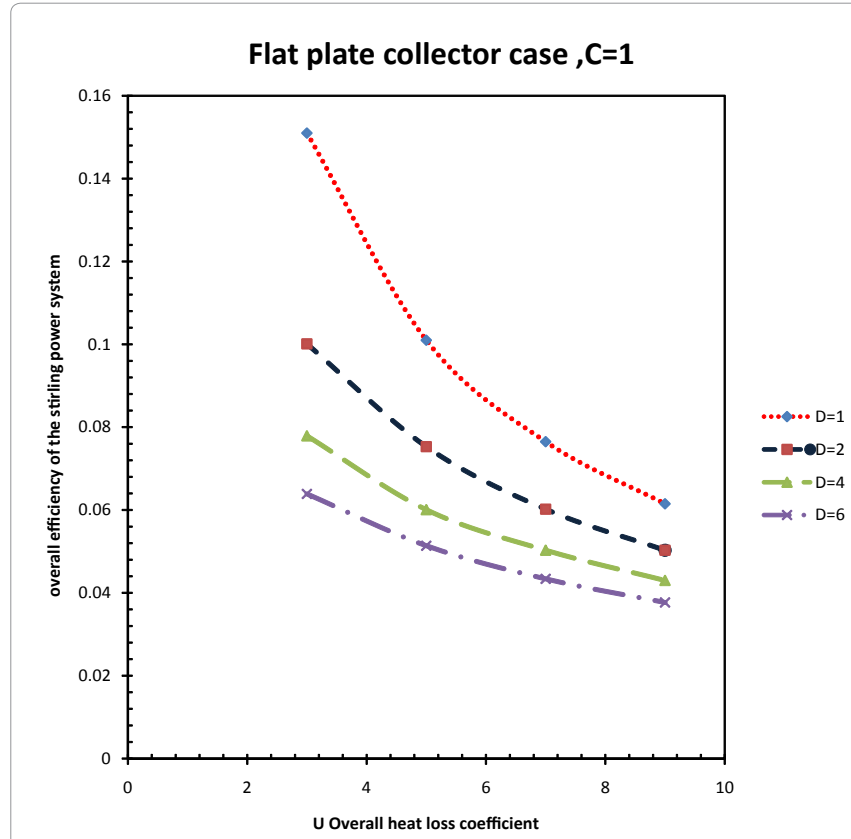

Figure 4: Dependence of the overall efficiency of the Stirling engine system on the overall heat loss coefficient (U).

values in comparison to the system based on a concentrating collector of moderate concentration $(\mathrm{C}=200)$ (Figure 5 ). It is because radiative losses are of a predominant nature for concentrating collectors. Figure 4 and 5 shown that with increased overall heat loss coefficient

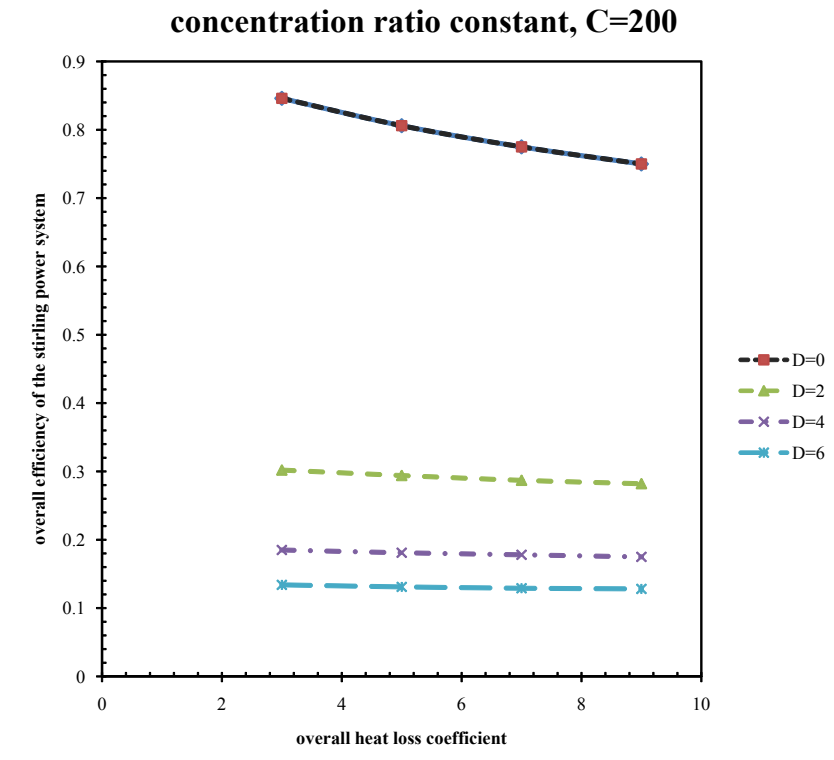

Figure 5: Dependence of the overall efficiency of the Stirling power system on the overall heat loss coefficient $(U)$

in constant concentration ratio, overall efficiency of Stirling power system decreased which this reduction for flat plate solar collector is more rapidly than concentrating collector. The result shows that concentrating collector-based Stirling power systems are considerably more efficient in comparison to those based on flat plate collectors.

\section{Conclusions}

Overall efficiency of Stirling power system has strong dependence on the concentration ratio. As seen maximum system efficiency obtained on optimum operating temperature ratio which optimum operating temperature ratio dependence to concentration ratio and engine parameters. Therefore, performance of Stirling power system is very sensitive to changing in concentration ratio. As show in Figure 2 in the constant engine parameters by increasing concentration ratio, efficiency is increased. Also in constant concentration ratio by increasing overall heat loss coefficient slop of efficiency reduction of system is decreased by this reason we don't recommend using of flat plate solar collector.

\section{Nomenclature}

Q Rate of energy, $\mathrm{W} \mathrm{m}^{-2}$

$\mathrm{U}$ Overall convective heat loss coefficient of the collector, $\mathrm{W} \mathrm{m} \mathrm{m}^{-2} \mathrm{~K}^{-1}$

$\varepsilon$ Emissivity factor

$I$ Irradiance

$x$ The fractional deviation from ideal regeneration

$v$ Specific volume, $\mathrm{m} \mathrm{Kg}^{-1}$

$C_{v}$ Specific heat capacity, $\mathrm{J} \mathrm{mol}^{-1} \mathrm{~K}^{-1}$

$p$ Power, $\mathrm{W}$

$\eta$ Thermal efficiency

$T$ Temperature, $\mathrm{K}$

$(\tau \alpha)$ Effective product transmittance-absorptance 
Citation: Ahmadi MH, Hosseinzade H (2012) Investigation of Solar Collector Design Parameters Effect onto Solar Stirling Engine Efficiency. J Applied Mechanic Engg 1:102. doi:10.4172/2168-9873.1000102

\section{Subscripts}

$s$ Black-body

$o$ Atmospheric

$c$ Stirling engine

\section{References}

1. Walker G, Fauvel OR, Reader G (1989) The literature of Stirling engine. Energy Conversion Engineering Conference, IECEC-89. Proceedings of the 24th Intersociety 5: 2337 - 2340.

2. Allan J Organ, T Finkelstein (1992) Thermodynamics and Gas Dynamics of Stirling Cycle Machine. Cambridge University press.

3. Walker G (1994) The Stirling alternative: Power systems, Refrigerants and Heat Pumps. Gordon and Breach Science Publishers, Switzerland.

4. William Beale (1985) Understanding Stirling engines. Vita publications

5. Organ AJ (1997) The regenerator and Stirling engine, wiley.

6. David A Trayser, James A Eibling (1967) A 50-watt portable generator employing a solar powered Stirling engine. Solar Energy 11: 153-159.

7. Gan ZH (2008) Study on 5.0W/80K single stage Stirling type pluse tube cryocooler. Journal of Zhejiang university Science A 9: 1277-1282.

8. Slaby JG (1985) Overview of the 1985 NASA Lewis Research Centre SP-100 Free-piston stirling engine ctivities. NASA-TM-87028; CONF-850808-12.

9. Shaltens RK (1987) Comparison of Stirling engines for use with a $25 \mathrm{~kW}$ dishelectric conversion system. NASA TM-100111-AIAA-87-9069.

10. Alger D (1988) component Improvement of FPSE Key Technology for Space Power. NASA technical memorandum, 100950

11. Jin-Soo Kim, Yong-Heack Kang, Sang-Nam Lee, Hwan-Ki Yoon, ChangKyun Yu, et al. (2009) Operation results of dish-Stirling solar power system. Proceedings of ISES World congress 2007 5: 1854-1857.

12. Tlili S, Timoumi Y, Ben Nasrallah S (2008) Analysis and design consideration of mean temperature differential Stirling engine for solar application. Renewable Energy 33: 1911-1921.

13. Dhar M (1990) UNDP mission report on Stirling engine technology in India. IND/86/002.

14. Sootha GD, Moham S, Singh N (1991) Stirling engines-need, potential and constraints for Indian conditions. Proc. 5th I.S.E.C. Paper 071.

15. Said N, Tedjia B (1988) Optimum working temperature for a dish-Stirling module. Paper 049,Proc. 4th I.S.E.C.,;pp. 243-246.
16. Kongtragool Bancha, Somchai Wongwises (2005) Optimum absorber temperature of a once-reflecting full conical concentrator of a low-temperature differential stirling engine. Renewable Energy 30: 1671-1687.

17. Howell JR, Bannerot RB (1977) optimum solar collector operation for maximizing cycle work output. Solar energy 19: 149-153.

18. Badescu V (1992) Optimum operation of a solar converter in combination with a Stirling or Ericsson heat engine. Energy 17: 601-607.

19. Selcuk MK (1986) "Prediction of Performance of Paraboloid dish solar-power Modules Using Graphical Methods" in solar energy Utilisation. Fundamentals and Applications: 543-563,H. Yuncu and B. Kilkis eds., EIEl Printing Shop Ankara, Turkey.

20. Constantinescu R, Costea M, Mladin C, Brusalis T, Petrescu S (1988) Bull. Inst Polytechnique de Bucarest 50: 59.

21. Petrescu S, Brusalis T, lordache R, Costea M, Petrescu V (1989) Energetica 37: 358.

22. Kongtragool B, Wongwises S (2003) A review of solar powered Stirling engines and low temperature differential Stirling engines. Renewable \& Sustainable Energy Reviews 7: 131-154.

23. Kongtragool B, Wongwises S (2003) Theoretical investigation on beale numbe for low temperature differential Stirling engines. Proceedings of the second international conference on heat transfer, fluid mechanics and thermodynamics.

24. Kongtragool B, Wongwises S (2005) Investigation on power output of gammaconfiguration low temperature differential Stirling engines. Renewable Energy 30: $465-476$.

25. Badescu V (1991) Note concerning the maximal efficiency and the optimal operating temperature of solar converters with or without concentration. Renewable Energy: 131-135.

26. Petrescu S, Brusalis T, lordache R, Costea M, Petrescu V (1989) Energetica 37: 358.

27. Walpita SH (1983) Development of the solar receiver for a small Stirling engine, Special study project report no. ET-83-1. Bangkok: Asian Institute of technology: 33.

28. Woodman TP (1977) The effect of design and operating parameters on the performance of flat plate solar collectors-calculation method and detailed appraisal. Solar Energy 19: 263-270.

29. Eldighidy SM (1993) Optimum outlet temperature of solar collector for maximum work output for an otto air standard cycle with ideal regeneration. Solar Energy 51: 175-182. 